\title{
La identidad lírica de Conrado del Campo en los retablos de Víctor Espinós
}

\section{The Operatic Identity of Conrado del Campo in Victor Espinós' Retablos}

Los pocos estudios realizados hasta la fecha sobre la figura de Conrado del Campo han coincidido en señalar su gran temperamento lírico, cualidad que se refleja en su catálogo en más de 25 títulos, entre óperas, zarzuelas y otros géneros de música teatral. En este trabajo proponemos una aproximación a la lírica del maestro a partir de una sección muy concreta de su producción, la música escrita para los retablos deVíctor Espinós entre 1927 y 1930: Antaño o un corpus viejo en Madrid (1927), El cielo y Madrid se casan (1928), El retablo de fray Luis (1928) y El retablo de los remedios (1930). Usando la teoría de tópicos, nos acercaremos a estas obras para mostrar alguna de las prácticas compositivas que Del Campo ensayó durante ese momento de su vida para plasmar su concepción de la identidad lírica española en un género tan particular como el retablo musical.

Palabras clave: Conrado del Campo,Víctor Espinós, tardo-romanticismo, tópico musical, cadencia andaluza, identidad lírica española.

The few studies that have been published to date about Conrado del Campo have highlighted his great temperament for theatre music, a quality that is reflected in his large catalogue with more than 25 works, including operas, zarzuelas and other genres for the stage. This study examines the composer's theatre music, considering the works he composed for Victor Espinós' retablos between 1927 and 1930: Antaño o un corpus viejo en Madrid (1927), El cielo y Madrid se casan (1928), El retablo de fray Luis (1928) y El retablo de los remedios (1930). Using topic theory, these works will be analysed to show some of the compositional practices Del Campo trialled at this point of his life in order to reflect his conception of the Spanish operatic identity within a genre as peculiar as the musical retablo.

Keywords: Conrado del Campo, Victor Espinós, late-Romanticism, musical topic, Andalusian cadence, Spanish operatic identity.

El lugar que ocupa el compositor Conrado del Campo (1878-1953) en el discurso historiográfico que la musicología española ha generado en los últimos años resulta un tanto contradictorio. Si bien no hay duda en considerarlo como uno de los grandes compositores del panorama musical madrileño del primer tercio del siglo XX, su obra ha permanecido injustamente olvidada -tanto por estudiosos como por intérpretes-, salvo contados ejemplos en relación a su creación camerística y, en menor medida, a su 
producción lírica ${ }^{1}$. Las razones de esta desatención, en nuestra opinión, responden a la complejidad que supone el simple acercamiento inicial al propio legado del compositor, pues nos ha dejado un catálogo muy nutrido, con un total aproximado de 219 obras, que incluye partituras de todos los géneros: música de cámara, sinfónica y teatral ${ }^{2}$. A ello, además, hemos de añadir por un lado la intrincada caligrafia del autor -que no acostumbraba a pasar a limpio sus manuscritos- y una plantilla orquestal a menudo desmesurada, al estilo wagneriano, que dificulta todavía más, si cabe, no solo el estudio de la música, sino también su edición e interpretación. Finalmente, no podemos dejar de mencionar el hecho de que Conrado del Campo no se adecua al modelo estético e identitario propuesto por la línea Pedrell-Falla-Salazar, condicionante que, sin ninguna duda, lo ha situado en un segundo plano.

Todo lo que acabamos de comentar pone en evidencia la necesidad de comenzar cuanto antes a elaborar estudios rigurosos sobre su obra que lo sitúen de forma clara en el contexto histórico al que pertenece y que den a conocer su participación activa en la construcción -junto a otros actores de igual importancia y perfil estético similar- de esa "otra" identidad musical española. Para afrontar esta tarea, y debido a su ingente catálogo, se hace necesario acotar la investigación sobre algún elemento concreto de su música. En este sentido, los pocos estudios que se han hecho hasta la fecha en torno a alguno de los múltiples aspectos que se desprenden de su polifacética figura han coincidido en señalar, por encima de lo demás, su enorme temperamento lírico. Esta cualidad, que ha captado por completo nuestra atención, le llevó a producir un corpus que sobrepasa los 25 títulos,

\footnotetext{
${ }^{1}$ En el campo de la edición, podemos citar las realizadas por la Editorial de Música Española Contemporánea sobre Fantasía castellana (1947) publicada en 1982; las dos partes de la Divina comedia (1908-1910) en el año 2001 y Seis pequeñas composiciones para orquesta y pequeño coro sobre versos de Góngora (1927) en 2002; los cuartetos de cuerda n. ${ }^{\circ} 5$ (1907-1908) y 13 (1949), publicados respectivamente en 1923 y 1949 por Unión Musical Española; y la edición facsímil de la ópera Fantochines (1923) realizada por Antonio Gallego y publicada por la Fundación Juan March en 1990. Asimismo, en lo referente a estudios científicos, hemos de mencionar el trabajo de Christiane Heine sobre el magisterio de Conrado del Campo, Christiane Heine: "El magisterio de Conrado del Campo en la generación del 27: el caso de Salvador Bacarisse y Ángel Martín Pompey", Música española entre dos guerras, 1914-1945, Javier Suárez-Pajares (ed.), Granada, Publicaciones Archivo Manuel de Falla, 2002, pp. 99131; y los estudios en torno a la ópera de Víctor Sánchez: "Análisis de las primeras óperas de Conrado del Campo: entre Wagner y el nacionalismo", Revista de Musicología, XXVII, 1, 2005, pp. 764-773; id.: "Resonancias tristanescas en la ópera española: Wagnerismo en las óperas de Conrado del Campo", Anuario Musical, 65, 2010, pp. 145-170; id.: "El 'Germanismo violento' en la obra de Conrado del Campo", Cruces de caminos: intercambios musicales y artísticos en la Europa de la primera mitad del siglo XX, Gemma Pérez Zalduondo, María Isabel Cabrera García (coords.), Granada, Editorial Universidad de Granada-Université François-Rabelais de Tours, 2010, pp. 218-261.

${ }^{2}$ Miguel Alonso: Catálogo de obras de Conrado del Campo, Madrid, Fundación Juan March, 1986 Se trata de una ordenación de los apuntes realizados por Ricardo del Campo, hijo del compositor. Una revisión de este catálogo fue publicada por la Sociedad General de Autores en 1998, adaptado a los criterios de la colección "Catálogos de Compositores" y con la coautoría, junto a Miguel Alonso, de Álvaro García Estefanía.
} 
entre ópera, zarzuela y diversos títulos de género chico y música teatral. Es por ello que hemos iniciado un trabajo más amplio centrado en el estudio de las óperas que compuso y estrenó entre 1910 y $1920^{3}$ con el objetivo principal de determinar los principales rasgos identitarios que caracterizan su producción lírica y situar sus óperas en el lugar que le corresponde dentro del complejo debate en torno a los ideales de la ópera nacional $-\mathrm{O}$, si se prefiere, nacionalista- española.

Sin embargo, en este trabajo hemos optado por centrarnos en un conjunto de obras cronológicamente posterior con el propósito de poder observar el estado de su práctica lírica en un momento más tardío al que comentaba en el párrafo anterior. Se trata de un grupo de cuatro composiciones de teatro musical que surgen de la colaboración de Conrado del Campo con Víctor Espinós entre 1927 y 1930, y que se identifican bajo la etiqueta de un género muy concreto y particular denominado retablo: Antaño o un corpus viejo en Madrid (1927), El cielo y Madrid se casan (1928), El retablo de fray Luis (1928) y El retablo de los remedios (1930).

Por lo tanto, nos acercaremos a estas obras con el objetivo de sacar a la luz alguna de las prácticas compositivas que Conrado del Campo empleó durante ese momento de su vida para plasmar su concepción de la identidad lírica española. Además, este trabajo supondrá una suerte de cata dentro de su catálogo que nos permitirá observar el estado de su pensamiento estético en un periodo concreto y acotado para una ulterior comparación con el inicial una vez hayamos concluido ese análisis de las primeras óperas. Para ello, empezaremos por explicar el planteamiento metodológico empleado, la teoría de tópicos musicales, y las razones de su elección; continuaremos con una aproximación biográfica a los dos autores implicados que nos permitirá entender sus circunstancias vitales en aquellos años y con una descripción del género de los retablos; y, finalmente, abordaremos el análisis en las cuatro obras elegidas de un tópico musical concreto, la cadencia andaluza, con el fin de comprender, no solo sus implicaciones musicales sino también sus consecuencias estéticas.

\section{Esbozo metodológico: la teoría de los tópicos musicales}

Para dar cumplimiento al objetivo planteado vamos a emplear una metodología basada en enfoques semiológicos que supere la pura descripción musical y permita explorar la identidad de nuestro protagonista. Solo así conseguiremos evitar que nuestro estudio trate las obras musicales como entes aislados, ya que entendemos que es necesario integrar cada composición

${ }^{3}$ Nos referimos a El final de don Álvaro (1910), La tragedia del beso (1911), y El Avapiés (1918), esta última compuesta en colaboración con el músico andaluz Ángel Barrios. 
-y las reacciones que produjo en el público y la crítica- en su contexto histórico más inmediato, según los preceptos marcados por la historia cultural e intelectual. Por ello, nos basaremos en dos teorías principales: en primer lugar, la ya clásica tripartición de Molino y Nattiez -niveles poiético, neutro y estésico-, actualizada por los postulados de la musicología postmoderna y adaptada convenientemente a cuestiones de índole identitaria; y, en segundo lugar, la teoría de los tópicos musicales, ya que consideramos que se trata de una herramienta que puede proporcionar, no solo la visión estratégica que sigue una obra como ente individual sino que también permitirá definir un estilo general y una identidad musical propia, la de Conrado del Campo.

El modelo tripartito está totalmente asumido por la mayoría de la musicología española que lo integra en sus estudios como un telón de fondo constante sobre el que ya no conviene teorizar en exceso. Sin embargo, queremos dar unas explicaciones que maticen su aplicación en nuestro trabajo. La esencia de este modelo parte de que la obra musical no es solamente la partitura (nivel neutro), sino que también intervienen los procesos que la han hecho nacer (nivel poiético, o de la creación), y a los que ha dado lugar (nivel estético, o de la recepción), tal y como han establecido Jean Molino ${ }^{4}$ y Jean-Jacques Nattiez ${ }^{5}$ en sus estudios de referencia. Sin embargo, y a pesar de que estos tres niveles están estrechamente relacionados entre sí y se complementan unos a otros, observamos un cierto estatismo, sobre todo en lo relativo al significado que desprenden. Por lo tanto, se hace necesario buscar un modelo que interprete los elementos estudiados en cada nivel y nos permita entender las consecuencias que tuvo en el contexto general al que pertenecen. La clave reside en aplicar una metodología que, como defiende Carlos Villar, se base "en la vigencia de los paradigmas teóricos resumidos en el binomio forma-significado y la necesidad de continuidad e indisolubilidad conceptual entre ambas facetas del pensamiento musical"'. En este sentido, resulta oportuno traer a colación el trabajo de Giles Hooper titulado The Discourse of Musicology en el que llama la atención sobre la necesidad de interpretar la música en función del contexto en el que esta se experimenta, proponiendo así tres esferas de mediación -estructural/institucional, productiva y receptiva-, lo que supone una auténtica actualización del modelo tripartito de Molino y

\footnotetext{
${ }^{4}$ Jean Molino: "Fait musical et sémiologie de la Musique", Musique en Jeu, 17, 1975, pp. 37-62. 1976.

${ }^{5}$ Jean-Jacques Nattiez: Fondements d’une sémiologie de la Musique, París, Union Générale d'Éditions,

${ }^{6}$ Carlos Villar-Taboada: "De la técnica al significado: debates y modelos en torno al análisis atonal", Música, ciencia y pensamiento en España e Iberoamérica durante el siglo XX, Leticia Sánchez de Andrés, Adela Presas (eds.), Madrid, Universidad Autónoma de Madrid, 2013, p. 164.
} 
Nattiez ${ }^{7}$. En otras palabras, se trata de integrar la obra en su contexto para poder extrapolar los rasgos identitarios de, en este caso, una parte de la producción lírica de Conrado del Campo.

La herramienta que emplearemos para poner en marcha el mecanismo anterior será la teoría de los tópicos musicales, que fue formulada por primera vez en 1980 por Leonard Ratner en un importante trabajo sobre la música del siglo XVIII. Como marco teórico de referencia remitimos al artículo de Nicholas Mckay titulado "On Topics Today" en el que hace un recorrido por la evolución de esta teoría y distingue dos generaciones principales de estudiosos: la primera, formada por Leonard Ratner ${ }^{9}$ y sus dos discípulos Kofi Agawu ${ }^{10}$ y Wye Allanbrook ${ }^{11}$; y la segunda, encabezada por los trabajos de Robert Hatten ${ }^{12}$ y Raymond Monelle ${ }^{13}$. Todos ellos han establecido con sus discursos -no siempre coincidentes, de ahí su riqueza- un diálogo estable y constante entre forma y significado, en el que los tópicos no son tratados como simples etiquetas, sino que son vistos también como elementos dotados de una fuerte carga hermenéutica que permite integrar la música en un contexto mucho más amplio. Como complemento a esta definición, podemos añadir, por su carácter clarificador, los planteamientos de Rubén López Cano, que relaciona el tópico musical "con ese punto cognitivo en el que el escucha (o público) competente comienza a construir mundos específicos con el objeto sonoro, gracias a la articulación de marcos y guiones que orientarán su semiosis musical", considerando el tópico, por lo tanto, como un "pivote para la cognición"14.

Sin embargo, la puesta en marcha de este tipo de metodología requiere de un trabajo previo que, tal y como establece Kofi Agawu ${ }^{15}$, consiste en

\footnotetext{
${ }^{7}$ Giles Hooper: The Discourse of Musicology, Aldershot (UK), Ashgate, 2006, pp. 73-84

${ }^{8}$ Nicholas Mckay: "On Topics Today", Zeitschrift der Gesellschaft für Musiktheorie, 4, 1-2, 2007, pp. 159-183.

${ }^{9}$ Leonard Ratner: Classic Music: Expression, Form and Style, Nueva York, Schirmer books, 1980.

${ }^{10}$ Kofi Agawu: Playing with Sings: A Semiotic Interpretation of Classical Music, Princeton (NJ), Princeton University Press, 1991; id.: Music as a Discourse. Semiotic Adventures in Romantic Music, Oxford-Nueva York, Oxford University Press, 2009

${ }^{11}$ Wye Allanbrook: Rhythmic Gesture in Mozart: Le nozze di Figaro and Don Giovanni, ChicagoLondres, University of Chicago Press, 1983.

12 Robert Hatten: Musical Meaning in Beethoven: Markedness, Correlation, and Interpretation, Bloomington (IN), Indiana University Press, 1994; Interpreting Musical Gestures, Topics and Tropes: Mozart, Beethoven, Schubert, Bloomington (IN), Indiana University Press, 2004.

${ }^{13}$ Raymond Monelle: The Sense of Music: Semiotic Essays, Princeton (NJ), Princeton University Press, 2000; id.: The Musical Topic: Hunt, Military and Pastoral, Bloomington, Indiana University Press, 2006.

${ }^{14}$ Rubén López Cano: "Entre el giro lingüístico y el guiño hermenéutico: tópicos y competencia en la semiótica musical actual", Revista Cuilcuilco, 9, 25, 2002. Número especial: Análisis del discurso y semiótica de la cultura: perspectivas analíticas para el tercer milenio, tomo II, p. 20; p. 42 (versión online: www.lopezcano.net, consulta 1-5-2016).

${ }^{15}$ K. Agawu: Music as a Discourse..., pp. 83-84.
} 
conocer el contexto musical que rodea a los creadores artísticos -en nuestro caso Conrado del Campo yVíctor Espinós- para entender sus mecanismos de comunicación con ese entorno, pues los tópicos pueden ser entendidos también como un diálogo a través de convenciones entre un público competente y el compositor. Así, y suscribiendo nuevamente las palabras de Agawu, "debemos construir un universo de tópicos desde el principio"16 en el que se integren los que son propios de cada compositor, algo que se puede realizar a partir de la numerosa bibliografía existente sobre la época en la que se inserta el repertorio que vamos a analizar (los retablos musicales). El modo en que cada músico emplee de forma consciente los tópicos que encuentra en su universo general (identidad colectiva) para influir en su público será la clave para poder hablar de rasgos identitarios en un plano personal que, como hemos planteado, es el objetivo de este trabajo.

\section{Los autores, el género y el contexto}

Conrado del Campo (1878-1953) se formó en la Escuela Nacional de Música de Madrid, actual Conservatorio Superior de la ciudad. Estuvo vinculado a esa institución durante toda su vida profesional, pues en 1915 se convirtió en uno de los catedráticos - de armonía primero y, desde 1923, de composición- del centro, que a partir del año 1900 pasó a denominarse Real Conservatorio de Música y Declamación. Como docente, y siguiendo los resultados de las investigaciones de Christiane Heine, ejerció una fuerte influencia sobre muchos de los músicos de la Generación del 27, aunque siempre haciendo gala de una gran apertura en su práctica docente, sin perder de vista el precepto de tratar de conservar la personalidad propia de cada uno de sus alumnos ${ }^{17}$. Además de esta faceta pedagógica, durante su primera etapa vital llevó a cabo una carrera muy activa e intensa como instrumentista. En este sentido, y si bien el violín había sido su punto de partida, fue la viola el instrumento con el que más se dio a conocer y con el que alcanzó un éxito rotundo, tanto en agrupaciones camerísticas como en orquestas, principalmente en la del Teatro Real, donde estrenó e interpretó sus propias óperas.

Sin embargo, en el lapso temporal en el que se inserta la presente investigación (1927-1930) Conrado del Campo había dejado ya su puesto como viola solista en el foso del Real, obligado por el cierre del teatro en 1925; y el Quinteto de Madrid, agrupación camerística de la que había formado parte desde sus inicios (al principio constituida por cuatro componentes y conocida como Cuarteto Francés), también se había disuelto

\footnotetext{
${ }^{16}$ Ibid. p. 84.

${ }^{17}$ C. Heine: "El magisterio de Conrado del Campo...", pp. 99-131.
} 
aquel mismo año ${ }^{18}$. Con todo, la desaparición de este grupo supuso la creación de una nueva formación, la agrupación Unión Radio, que estuvo en activo hasta el alzamiento militar de 1936 y en la que Conrado tomó parte también con su viola. Por lo tanto, y más allá de los principales debates ideológicos de esos años, sus principales influencias proceden de su práctica musical anterior: en el ámbito lírico, todas las óperas que interpretó con la orquesta del Teatro Real (destacando los dramas líricos de Richard Wagner); y a nivel camerístico, a través del ingente repertorio trabajado por el Cuarteto Francés primero y el Quinteto de Madrid después. Todo ello estará plasmado, en mayor o menor medida, en el repertorio que aquí tratamos. Por otro lado, la siguiente etapa en la vida de nuestro protagonista se iniciaría a partir de 1932, con su ingreso en la Real Academia de Bellas Artes de San Fernando y el comienzo de su actividad como director de orquesta sinfónica ${ }^{19}$.

Víctor Espinós (1871-1948) fue también un personaje polifacético e influyente en su época: abogado, musicólogo, compositor, crítico musical y dramaturgo ${ }^{20}$. Como es bien sabido, llevó a cabo una valiosa actividad de difusión musical a través de la creación en 1919 de la Biblioteca Municipal Circulante de Madrid, actualmente conocida como la Biblioteca $\mathrm{Mu}$ sical Víctor Espinós que se emplaza en el Centro Cultural Conde Duque. Como musicólogo destacó por la elaboración de trabajos en torno a

${ }^{18}$ El Cuarteto Francés estuvo integrado por Julio Francés, violín primero que le daba el nombre a la agrupación, Odón González como violín segundo, Conrado del Campo a la viola y Luis Villa con el violonchelo. Más tarde, cuando se formó el Quinteto de Madrid, al grupo anterior se unió Joaquín Turina como pianista.

${ }^{19}$ Por el momento no existe ningún texto sobre Conrado del Campo que trate su biografía de una forma seria y ordenada. Muchos de los datos que hemos comentado en este breve esbozo proceden de los trabajos citados en la introducción, mientras que otros fueron extraídos de un pequeño folleto biográfico escrito por Tomás Borrás: Conrado del Campo, Madrid, Instituto de Estudios Madrileños, 1954 (colección "Temas madrileños", vol. XIII). También ha sido una referencia fundamental Ramón García Avello: "Campo Zabaleta, Conrado del", Diccionario de la música española e hispanoamericana, Emilio Casares (dir.), Madrid, SGAE, 1999-2002, vol. 2, pp. 982-993.

Por otro lado, Ricardo del Campo, hijo del compositor, inició tras la desaparición de su padre la monumental tarea de acometer su biografía aunque, por desgracia, murió antes de completar el trabajo. Sin embargo, se conserva un conjunto de esbozos y apuntes -algunos manuscritos y otros a máquina- que dan forma a lo que pretendían ser los principales capítulos de la biografía de Conrado del Campo. Estos documentos fueron ordenados y sistematizados por Miguel Alonso, discípulo del compositor, al que también sorprendió la muerte antes de acabar la biografía de su maestro. Precisamente los apuntes de Ricardo del Campo se conservan dentro del legado personal de Miguel Alonso que está depositado en el archivo de la Sociedad General de Autores y Editores, en su sede de Madrid.

${ }^{20} \mathrm{Al}$ igual que ocurre con Conrado del Campo, tampoco existen hasta la fecha textos biográficos de gran calado sobre la figura de Víctor Espinós. Los datos que aquí se ofrecen sobre este importante personaje del ámbito cultural del primer tercio del siglo XX español proceden, en su mayoría, de Emilio Casares: "Espinós Moltó, Víctor Juan", Diccionario de la música española e hispanoamericana, E. Casares (dir.), Madrid, SGAE, 1999-2002, vol. 4, p. 780. Por otro lado, existe otra referencia del mismo carácter, un tanto más extensa que la anterior pero menos fiable, ya que cae en contradicciones básicas como la fecha de nacimiento: Ernesto Valor Calatayud: Catálogo de músicos alcoyanos, Alcoy, Instituto Alcoyano de Cultura Andrés Sempere, 1961, pp. 62-64. 
El Quijote y la música ${ }^{21}$, o su investigación sobre la figura de Enrique Fernández Arbós, que sigue siendo una de las obras de referencia sobre este insigne músico ${ }^{22}$. Una de sus actividades más constantes durante su vida, y quizás por la que es más recordado, fue la crítica musical, una faceta que le llevó a escribir en periódicos tan conocidos e influyentes como El Debate, $A B C$, El Español y El Universo. Todos sus escritos y composiciones literarias son un espejo en el que se refleja de forma muy clara su ideología, profundamente religiosa, conservadora y monárquica, siempre defendiendo la idea tan marcada que se tenía de patria española. Esta es precisamente la parte que más nos interesa, su obra literaria y el mensaje que quiso transmitir en ella, ya que además de escribir multitud de libretos y autos sacramentales, fue el creador de los retablos, género teatral (y también musical) que aquí nos ocupa.

Este tipo de obras teatrales, en las que como veremos la música juega un papel muy importante, puede ser definido prestando atención a tres testimonios de la época que creemos son muy reveladores. En primer lugar, Diego de Miranda, en un artículo de 1922 -por lo tanto antes de que se iniciara la colaboración entre Espinós y Conrado del Campo-, ofrecía una descripción del género en la que definía su argumento, la tipología de los personajes y su interés social y religioso, además de situar el estilo del dramaturgo a la altura del siglo de oro español:

Todas estas obras [los retablos] son afortunadas evocaciones históricas que sirven para presentar ante el espectador acertados cuadros populares de época y para hacer desfilar célebres figuras de nuestra religión y de nuestra historia. Felipe II y su corte; el rey Francisco I de Francia, cuando vino prisionero de Carlos V; San Ignacio de Loyola y San Francisco de Borja; San Isidro Labrador y Santa María de la Cabeza; estudiantes sopistas, infantes, mozas, corchetes y una porción de tipos populares de antaño adquieren vida por magia del señor Espinós, que ha sabido poner en los versos de todas sus obras primores de diálogo y bellezas de concepto, tan dignos de estima como los de los mejores autos sacramentales de los autores del siglo de oro.

Pero aún tienen estos retablos otro interés: el de la finalidad religiosa y patriótica. En todos ellos, por medio de loas, de prólogos, de himnos o de invocaciones, siempre oportunos y justificados, se exaltan y alientan los más puros sentimientos y los más elevados ideales. La fe, profetizando ciegamente un gran renacimiento católico en España; el bachiller de Decíamos ayer..., en la loa ante Francisco I, exponiendo anhelos de monarquía y patria, y otros muchos personajes representativos, realizan una evidente labor social, desde el tablado, en nombre del autor ${ }^{23}$.

\footnotetext{
${ }^{21}$ V. Espinós: Las realizaciones musicales del Quijote, Madrid, Espasa, 1933.

22 V. Espinós: El maestro Arbós, Madrid, Espasa-Calpe, 1942.

${ }^{23}$ Diego de Miranda: "Apuntes del momento. Los 'retablos' de Víctor Espinós”, Las Provincias, Valencia, 9-12-1922, p. 1.
} 
En segundo lugar, el conde de Cedillo, miembro de la Real Academia Española de la Historia, escribió un texto en el propio libreto de El retablo de fray Luis - una de las obras que se estudian en este trabajo- en el que incide en la similitud de los retablos con los autos sacramentales, utilizando ahora la figura de Calderón de la Barca como referente comparativo:

Los retablos de Víctor Espinós nos traen a la memoria, por dos razones, a los autos sacramentales de Calderón de la Barca... [Tanto] Unos como otros representan sendas lozanas, ramas del frondoso árbol de la literatura dramática que, si en sus entrañas y en sus formas de expresión se repara, no han tenido cosa igual en ningún tiempo y en ninguna literatura. Lo segundo, unos y otros parecen suscitados por el espíritu de la oportunidad... Víctor Espinós vive y canta en el siglo $\mathrm{XX}$ a un mundo menos capacitado y mucho [sic] olvidadizo, en el seno del cual florecen la leyenda negra y la insipiencia gris $^{24}$.

Sin embargo, también hubo quien supo ver las diferencias evidentes entre los retablos y los autos sacramentales, tal y como se pone de manifiesto en el tercer y último testimonio que ofrecemos. Como vemos, el redactor anónimo de esta nota de prensa considera -en nuestra opinión con gran acierto- que el retablo presenta una mayor agilidad dramática que el auto sacramental y que, además, la finalidad de aquel, desde el punto de vista teatral, es radicalmente distinta a la de este:

Comenzaremos por afirmar [...] que los retablos deVíctor Espinós [...] no son, como podría esperarse, continuación de un género de rancio y glorioso abolengo español, pero de escasa vistosidad y movimiento escénico: el auto sacramental.

Las evocaciones de Espinós son verdaderas obras teatrales, semejantes en un todo a la comedia o drama modernos, en lo que estos tienen de vida, de movimiento, de agilidad escénica. En esto se diferencian ya de los autos sacramentales, en los que la acción, el diálogo mismo, se resienten de [una] parquedad que les hace poco aptos para las exigencias del drama moderno.

Se diferencian también las evocaciones de Espinós de los autos sacramentales por la manera de considerar los motivos dramáticos, por la finalidad que con el desarrollo de los mismos se persigue -en las evocaciones se intenta fundamentalmente hacer teatro con la significación actual del vocablo- y por la manera de utilizar los recursos que el arte escénico proporciona ${ }^{25}$.

Por lo tanto, y en virtud de los textos anteriores -"no han tenido cosa igual en ningún tiempo y en ninguna literatura"-, estamos ante un género singular en el que se narra un acontecimiento concreto de la historia de España cargado con un fuerte contenido religioso, patriótico y moralizante, muy acorde con la ideología de su creador. Desde el punto de vista formal,

\footnotetext{
${ }^{24}$ Jerónimo López de Ayala: "Los retablos de Víctor Espinós", Víctor Espinós: El retablo de fray Luis, Madrid, Editora Nacional, 1947, pp. 13-14. Se trata de un texto que aparece junto a otros en una sección inicial, a modo de prólogo, que responde al título de "Juicios ilustres", pp. 11-14.

25 "La función de gala en el Bretón", El Adelanto, Salamanca, 13-5-1928, p. 5.
} 
los retablos se dividen en actos denominados jornadas, y estas, a su vez, en escenas. Normalmente comienzan con una loa breve de carácter alegórico, aunque hay algún caso, como el de Antaño, que se inicia directamente con la escena y presenta la loa al final.También es frecuente que aparezcan composiciones poéticas arcaicas, como el vejamen que se pronuncia al principio de El retablo de los remedios y que rememora un ambiente universitario más antiguo y anacrónico ${ }^{26}$. Quizás la mejor descripción, desde el punto de vista métrico y literario, nos la ofrece Juana Espinós Orlando -hija del escritor- quien menciona dos características esenciales:

La participación de la música y la combinación de la prosa y el verso; el romance y los de arte mayor son los más empleados aunque, para coplas y escenas populares, utiliza algunas veces los de arte menor. Sin embargo, podríamos decir que su forma predilecta de expresión son los endecasílabos y que rara vez emplea el verso libre y $\sin$ rima $^{27}$.

Uno de los grandes aciertos del género es la inclusión de ilustraciones musicales que pretenden transmitir los ambientes de la acción, elemento que contribuye a que la obra de teatro no se convierta en un espectáculo demasiado denso -las características descritas nos invitan a pensar que lo era- y se mantenga así la atención del público. Entre los compositores que se acercaron a este género y colaboraron con Víctor Espinós están Joaquín Turina, Julio Gómez, Salvador Bacarisse, Arturo Saco delValle y, en lo que nos atañe, Conrado del $\mathrm{Campo}^{28}$. Por otro lado, y más allá de la definición trazada para el retablo en función de la propuesta particular deVíctor Espinós, es importante aludir también a una tradición teatral popular preexistente en aquellos años con el mismo nombre -véase El retablillo de don Cristóbal (1930), de Federico García Lorca- y que, en música, a través de El retablo de Maese Pedro (1922) de Manuel de Falla, se relaciona con el teatro lírico de vanguardia ${ }^{29}$. Esto no hace más que poner de manifiesto una realidad que no conviene perder de vista: los trasvases culturales y estéticos de aquellos años hacen que los encasillamientos genéricos no queden del todo claros.

${ }^{26}$ La RAE define el vejamen -junto a dos acepciones más- como un "discurso o composición poética de índole burlesca, que con motivo de ciertos grados o certámenes se pronunciaba o leía en las universidades y academias contra quienes en ellos tomaban parte".

${ }^{27}$ Juana Espinós Orlando: "Los retablos madrileños de Víctor Espinós", Anales del Instituto de Estudios Madrileños, XX, Madrid, 1983, pp. 301-326.

${ }^{28}$ Salvador Bacarisse escribió la música de El marqués y el bachiller (1928); Julio Gómez para la adaptación de Las bodas de España (1928); Joaquín Turina para Salve: retablo mariano (1928); y Arturo Saco del Valle para La lección del príncipe (1928). Por otro lado, existe una obra que lleva por título Nacimiento (San Sebastián, 1938), "retablo de Navidad, el último que surgió de su pluma [la de Víctor Espinós]. [Trata] la Navidad española en los años dramáticos de la Guerra Civil en tres actos, cada uno de los cuales tiene música de un compositor diferente: [Emilio] Cotarelo, [Federico] Moreno Torroba y [Jesús] Guridi". Véase J. Espinós Orlando: "Los retablos madrileños...", p. 302.

${ }^{29}$ Véase Elena Torres Clemente: Las óperas de Manuel de Falla: de La vida breve al Retablo de Maese Pedro, Madrid, Sociedad Española de Musicología, 2007. 
En cuanto al contexto, la década de 1920 es bien conocida por ser el momento en el que la modernidad se instala de lleno en el panorama musical español. Los jóvenes compositores de la Generación del 27 emprenden en esos años el camino hacia la vanguardia, convirtiendo la Residencia de Estudiantes en uno de los epicentros de los que manaba la renovación de la música española ${ }^{30}$. Sin embargo, ni todos los compositores se sintieron atraídos por lo nuevo ni todo el público se mostraba abierto a las vanguardias -véase si no el estrepitoso fracaso final de la Sociedad Nacional de Música en $1922^{31}$ - lo que hacía necesaria la existencia de otros focos culturales acordes con los gustos más aferrados a la tradición. En este sentido, los retablos que aquí estudiamos son un claro reflejo de esa otra realidad: en primer lugar, las salas en las que se estrenaron y representaron evidencian ese ambiente continuista, ya que tanto el Teatro Real y el de la Zarzuela en Madrid, como el Bretón de Salamanca, no abanderaban precisamente la renovación musical, en contraste con otras instituciones más aperturistas, como la Residencia de Estudiantes o la Sociedad Nacional de Música. En segundo lugar, surgen en un contexto marcadamente católico sobre el que incidiremos al describir cada una de las obras estudiadas.

Finalmente, el público al que iban dirigidos encaja perfectamente con la estética que acabamos de comentar, ya que se componía de la nobleza, altos cargos eclesiásticos y militares, dirigentes de instituciones ultra católicas y la monarquía. Además, las fuentes hemerográficas evidencian una excelente acogida de los retablos, no solo por parte de esos estamentos sociales más elevados, sino también por las clases populares, ya que tanto el texto como la música reflejaban un ambiente que entroncaba con su propio imaginario cultural, más aferrado a la tradición popular y el catolicismo. A modo de ejemplo, ofrecemos el siguiente fragmento de la nota de prensa que se corresponde con el estreno en el Teatro Bretón de Salamanca de El retablo de fray Luis. En ella se ilustra a la perfección el ambiente que hemos descrito y además corrobora el éxito de estas representaciones entre la aristocracia y la realeza y nos permite intuir también la presencia de las clases populares en las butacas más humildes:

Se ha celebrado en el Teatro Bretón la anunciada función de gala con la asistencia de Su Majestad el Rey don Alfonso [XIII] y su Alteza Real la infanta Beatriz. [...].

Aspecto del salón:

${ }^{30}$ A modo de referencia contextual de lo que aquí comentamos, remitimos al lector a las siguientes fuentes bibliográficas: María Palacios: La renovación musical en Madrid durante la dictadura de Primo de Rivera. El grupo de los ocho (1923-1931), Madrid, Sociedad Española de Musicología, 2008; María Nagore, Leticia Sánchez de Andrés y Elena Torres (eds.): Música y cultura en la Edad de Plata 1915-1939, Madrid, ICCMU, 2009.

${ }^{31}$ David Ferreiro Carballo: La Sociedad Nacional de Música (1915-1922): historia, repertorio y recepción, trabajo de fin de máster, Madrid, Universidad Complutense, 2015. 
Como decimos antes, distinguido público de la buena sociedad salmantina ocupa palcos, plateas y casi todo el patio de butacas. Las demás localidades se hallan también ocupadas totalmente. El teatro se halla engalanado con gusto, especialmente en la parte ocupada por el palco regio, en el que colgaduras y tapices, constituyen el fundamental decorado. El antepalco se halla también amueblado con lujo, buen gusto y riqueza, adecuado a los regios huéspedes [la familia real] [...].

En las demás localidades, numerosísimo público, como se indica en otro lugar ${ }^{32}$.

Este es, por lo tanto, el contexto en el que surgen los retablos deVíctor Espinós para los que Conrado del Campo -y los demás compositores que hemos mencionado- compuso la música que se intercala entre las diferentes jornadas y escenas. Igualmente, y para finalizar este apartado, no queremos dejar de hacer una breve mención al hecho de que, según las fuentes consultadas, la puesta en escena de estas obras fue llevada a cabo siempre por actores aficionados -no así en el caso de los músicos y agrupaciones- que "con verdadero entusiasmo y en muchos casos con excepcional dignidad artística, dieron vida a sus personajes" 33 . Esta cuestión no hace más que redundar en esa otra realidad musical y social, alejada de la vanguardia y del elitismo cultural e intelectual, en la que se inserta el repertorio que estamos estudiando.

\section{El tópico de la cadencia andaluza en los retablos}

Tal y como hemos apuntado páginas atrás, Conrado del Campo se mostró siempre partidario de potenciar la personalidad de sus alumnos, y por eso nunca vetó en ellos la exploración vanguardista. Sin embargo, para su propio oficio prefirió mantenerse fiel a un estilo compositivo en el que se proyectan rasgos musicales propios de la segunda mitad del siglo XIX, en consonancia con algunos gestos, texturas y elementos armónicos del siglo XX. Esto, unido a su reconocido gusto por la música germana, hace que podamos situarlo como uno de los principales representantes de un tardo-romanticismo musical español. Por otro lado, este lenguaje musical se identifica con el contexto que trazamos en el punto anterior, lo que nos permite justificar la labor del compositor para con el género del retablo. En este sentido, una vez analizada la música, y puesta en relación con el contexto y el argumento teatral, se puede extraer una serie de tópicos musicales que refleja, no solo los ideales estéticos de Conrado del Campo, sino también su propia concepción de la identidad musical española. Para ilustrar esta idea, y empleando en todo momento la metodología expuesta, vamos a profundizar a continuación en el empleo que hace el compositor de un ejemplo concreto de tópico musical: la cadencia andaluza.

32 "La función de gala en el Bretón", El Adelanto, Salamanca, 26-5-1928, p. 5.

33 J. Espinós Orlando: "Los retablos madrileños...", p. 303. 
Para empezar, conviene definir de forma clara y precisa en qué consiste este elemento musical a nivel técnico y las razones que nos llevan a tratarlo como un tópico musical. Según la voz de Ramón Sobrino en el Diccionario de la música española e hispanoamericana, "se trata de una estructura cadencial típica, no solo de la música andaluza, sino de toda la música española, en la que se produce un descenso diatónico por grados conjuntos desde la dominante modal de la escala andaluza (La) hasta la nota final (Mi)" "34. Por lo tanto, estamos ante un motivo que comprende el primer tetracordo descendente del modo frigio (La-Sol-Fa-Mi), cuya armonización -extrapolable a todos los centros tonales-, por regla general empieza con un acorde perfecto mayor para el primer sonido de la cadencia (tercera mayor y quinta justa) y sigue con un acorde perfecto menor para el resto (tercera menor y quinta justa) ${ }^{35}$. En consecuencia, observamos un gesto musical muy recurrente, no solo en este momento específico, sino a lo largo de toda la historia de la música española, tanto popular como académica. Además, es reconocido por el público como un elemento que define claramente al objeto sonoro, lo que hace que podamos incluirlo, qué duda cabe, en el universo de tópicos general que menciona Kofi Agawu. Finalmente, el uso concreto del tópico por parte de Conrado del Campo establece un proceso de comunicación entre músico y público que nos permite definir la identidad lírica personal de este compositor.

Antes de comenzar con el análisis, queremos hacer una serie de consideraciones generales respecto a la instrumentación de las cuatro partituras, pues es prácticamente la misma en todas ellas: una orquesta formada por dos flautas, un oboe, dos clarinetes, un fagot, dos trompas en Fa, dos trompetas en Do, timbales, pequeña percusión y la sección de cuerda típica con dos voces para los violines. La única excepción se produce en el primer número de Antaño, en el que el compositor utiliza un quinteto de cuerda al que se le suma un piano. Como curiosidad, cabe señalar el empleo en el segundo número también de este retablo de dos pífanos en Re bemol en un contexto históricamente atribuido a este tipo de flautas: se trata de un ejemplo de música diegética que recrea un momento solemne al anunciar la llegada del rey y su séquito. Los manuscritos originales de los cuatro retablos -algunos incompletos- y las partes orquestales se conservan en Madrid, en el Centro de Documentación y Archivo (CEDOA) de la Sociedad General de Autores y Editores (SGAE) ${ }^{36}$.

\footnotetext{
${ }^{34}$ Ramón Sobrino: "Cadencia andaluza", Diccionario de la música española e hispanoamericana, E. Casares (dir.), Madrid, SGAE, 1999-2002, vol. 2, p. 860.

35 Para profundizar en los orígenes de la cadencia andaluza, remitimos al lector interesado al estudio clásico y de referencia de Josep Crivillé i Bargalló: Historia de la música española, 7: El folklore musical, Madrid, Alianza, 1983. De forma más precisa, véase en el capítulo titulado "Puntos de morfología" el apartado dedicado a "Sistemas modales y tonales", pp. 305-320.

${ }^{36}$ Antaño o un corpus viejo en Madrid (1927), fondo Conrado del Campo, sig. CONRADO/2.1; El cielo y Madrid se casan (1928), sig. AS-Caja 50; El retablo de fray Luis (1928), sig. AS-Caja 63; El retablo de los remedios (1930), sig. AS-Caja 63.
} 
El primer retablo de Víctor Espinós al que puso la música Conrado del Campo lleva por título Antaño o un corpus viejo en Madrid ${ }^{37}$, y fue estrenado el 31 de mayo de 1920 en el Teatro Real de la capital española con motivo de la primera Asamblea Nacional del Apostolado de la Oración ${ }^{38}$. Vemos aquí, por lo tanto, la presencia del ambiente religioso que comentamos antes tan ligado al pensamiento ideológico de Víctor Espinós, a los retablos y al contexto en el que se insertan. Conrado del Campo no escribió sus ilustraciones musicales hasta 1927, y las presentó el 25 de junio de ese mismo año en un concierto radiofónico interpretado por la Agrupación Unión Radio ${ }^{39}$. La acción nos lleva a una plaza madrileña de la segunda mitad del siglo XVI, durante el reinado de Felipe II, atestada de personajes típicos de la sociedad del momento: estudiantes, vendedores, pícaros, comediantes, ciegos cantores, etc. También aparecen personajes nobles, como la princesa Isabel y su padre Felipe II. Formalmente se compone de una única jornada dividida en cinco escenas: la de los estudiantes, la del ciego que entona dos coplas de Enríquez de Valderrábano, la de los caballeros, la de los truhanes y la de la niña. Todos ellos están esperando a que pase por la plaza la procesión del Corpus Christi, evento religioso al que se hace mención en el título del retablo. Al final se incluye la representación de una farsa sacramental anónima del siglo XVI que tiene lugar en la misma plaza y a la que asisten todos los personajes, titulada Las bodas de España, lo que supone un ejercicio de teatro dentro del teatro ${ }^{40}$.

Musicalmente, el retablo presenta cinco números de los cuales solamente el primero, el cuarto y el quinto -este último no se conserva- fueron escritos por Conrado del Campo. Los números dos y tres se corresponden con las coplas de Valderrábano que hemos mencionado en el párrafo anterior y que están sacadas del Cancionero de Palacio ${ }^{41}$. El ejemplo musical que mostramos a continuación procede del primer número, que suena a modo de preludio y durante la escena de los estudiantes. Se está musicalizando, por lo tanto, el ambiente general de la plaza madrileña en la que se desarrolla la acción. Como vemos, en un contexto tonal de Fa mayor, se produce al final una cadencia andaluza en la que el compositor se recrea sobre la primera nota del tetracordo, el Si bemol, y la resuelve en la tónica

37 V. Espinós: Antaño o un corpus viejo en Madrid, Madrid, Imprenta de Alberto Fontana, 1922.

38 "Nota Real. Festival artístico", La Correspondencia de España, Madrid, 1-5-1920, p. 6.

39 Según informa una nota escrita en el manuscrito original de la obra que se conserva en la SGAE.

${ }^{40}$ Años más tarde Víctor Espinós escribió también un retablo en el que hacía una adaptación de esta obra y, tal y como hemos apuntado páginas atrás, fue el compositor Julio Gómez el encargado de aportar las ilustraciones musicales.

${ }^{41}$ El propio Víctor Espinós ofrece en el libreto una reproducción facsímil del folio CXXXV del Cancionero de Palacio en la que se recoge la melodía principal de La bella malmaridada, de Gabriel Mena, para la cual compuso las partes de vihuela Enríquez de Valderrábano y que es una de las que se ejecutan en este retablo. V. Espinós: Antaño o un corpus viejo en Madrid..., p. 19. 
que da inicio a la siguiente sección (tetracordo Sib-Lab-Solb-Fa). Todo ello viene precedido de un pasaje melódico en el que conviven dos melodías de carácter popular con un acompañamiento armónico sencillo caracterizado por el empleo de notas largas a modo de pedal.
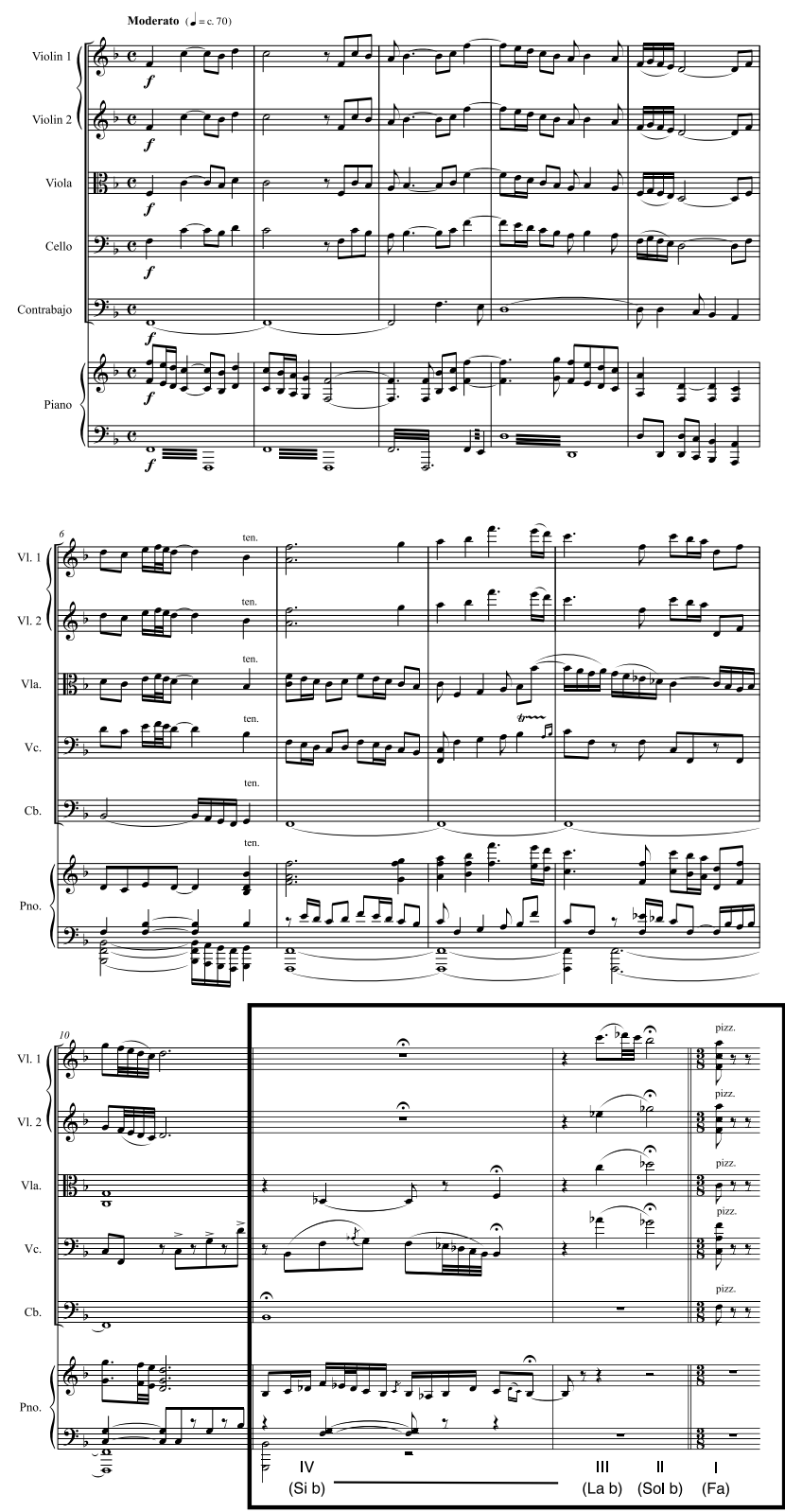

Ejemplo 1. Antaño o un corpus viejo en Madrid, $n .^{o} 1, c c .1-13$ 
El siguiente retablo, El cielo y Madrid se casan, presenta una génesis similar a la del anterior.Víctor Espinós lo escribe en 1922 y se estrena el 30 de mayo de ese año en el Teatro Real de Madrid durante los actos conmemorativos del tercer centenario de la canonización del patrón de la ciudad, San Isidro Labrador, por lo que volvemos a encontrar aquí una motivación religiosa ${ }^{42}$. Ambientada en el siglo XII, narra escenas de la vida de San Isidro y su matrimonio con Santa María de la Cabeza. Nuevamente los personajes de procedencia popular -como leñadores, pastores y cazadoresconviven con otros más nobles - como el caballero Juan de Vargas y su esposa-, lo que contribuye a remarcar el ambiente medieval en el que se sitúa la acción. Formalmente se compone de una jornada dividida en diez escenas, precedida de una loa y seguida de un homenaje en verso a la villa de Madrid. Conrado del Campo terminó su partitura en mayo de $1928^{43}$ y el estreno tuvo lugar en el Teatro Bretón de Salamanca el 27 de ese mismo mes, con motivo de las celebraciones por el centenario de fray Luis de León ${ }^{44}$. Musicalmente presenta cinco números, que reflejan un ambiente misterioso con sonoridades medievales, muy acorde a la narración de la vida milagrosa del santo.

El siguiente ejemplo que ofrecemos aparece en el primer y tercer número de la obra, aunque debemos aclarar que se trata exactamente del mismo material, ya que el compositor no lo escribe dos veces, sino que lo manda copiar directamente del primero. Se trata de una cadencia andaluza sobre el centro tonal de Do\# que nunca llega a resolver en su fundamental (tetracordo Fa\#-Mi-Re-[Do\#]), aunque no por ello dejamos de percibir su sonoridad. En el tercer número, este pasaje vuelve a sonar antes del baile para la celebración del matrimonio entre San Isidro Labrador y Santa María de la Cabeza y se produce después de que un zagal lance vítores a Juan de Vargas, es decir, ensalce la nobleza española. Como vemos, la cadencia no presenta ningún tipo de reelaboración especial y se inserta dentro de una textura de melodía acompañada, con tintes populares y en un estilo muy fiel al sinfonismo decimonónico español.

También al final del primer número de este retablo se puede observar una cadencia andaluza muy clara, en el último compás, en la voz de oboe. Esta se produce después de un pasaje largo marcado por sonoridades tenues y misteriosas; plagado de polirritmias evidentes y grupos de valoración especial; y con un desarrollo melódico y armónico cromático que entronca

${ }^{42}$ V. Espinós: "El cielo y Madrid se casan", Libro del tercer centenario de la canonización de San Isidro (1622-1922), Madrid, Imprenta del Asilo de Huérfanos del Sagrado Corazón de Jesús, 1922, pp. $161-207$.

${ }^{43}$ Firma y fecha en el manuscrito original de la obra que se conserva en la SGAE.

44 "El cielo y Madrid se casan", El Adelanto, Salamanca, 29-5-1928, p. 8. 
perfectamente con el germanismo imperante en el estilo del compositor. Con esta cadencia (tetracordo Fa\#-Mi-Re-Do\#) parece, por lo tanto, que a pesar de la sonoridad imperante en el retablo -medievalista, por la época, y misteriosa, por el misticismo de San Isidro- Conrado del Campo nos quiere recordar que, ante todo, y pese al estilo germanizante, la acción tiene lugar en la capital de España.
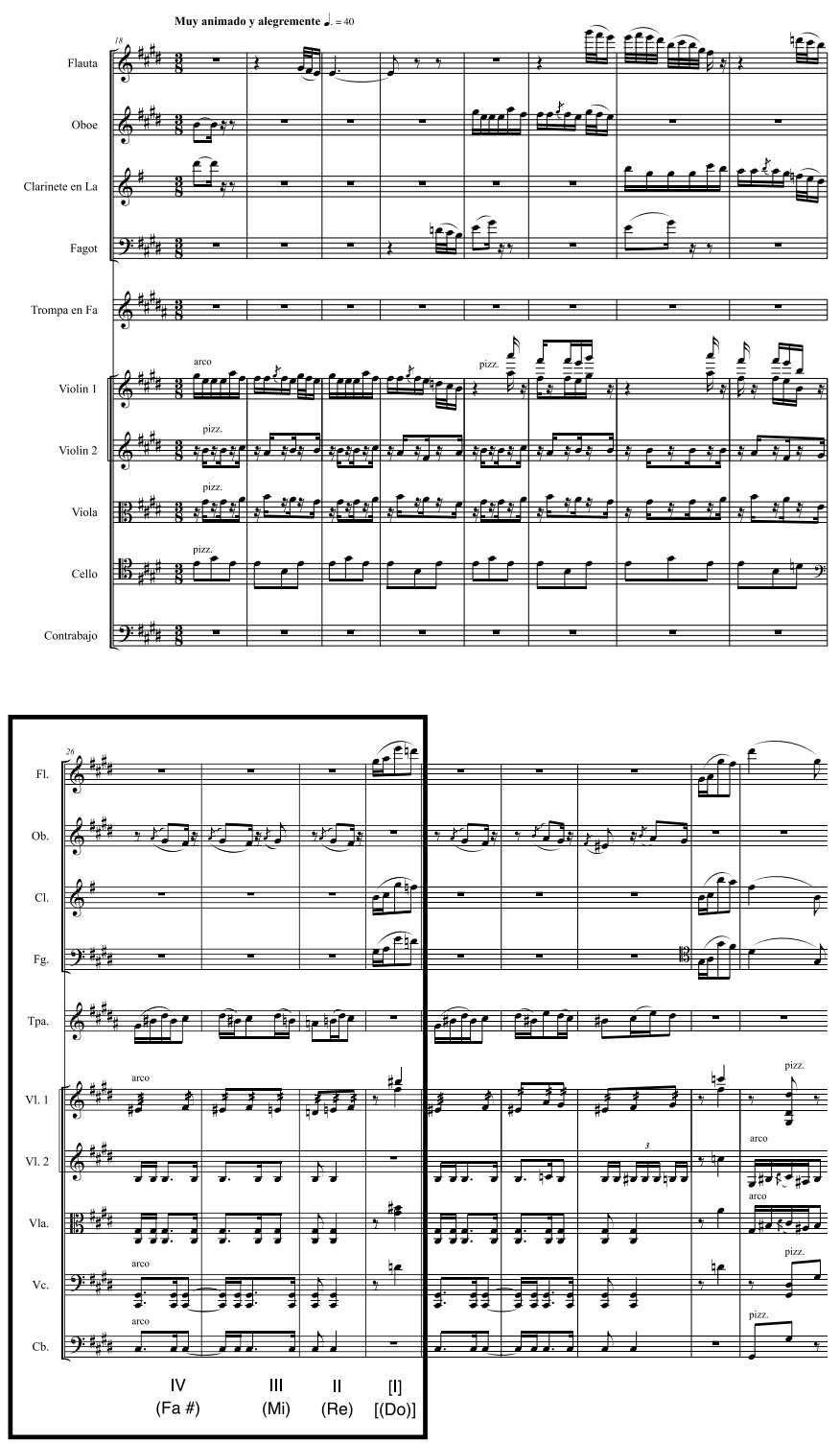

Ejemplo 2. El cielo y Madrid se casan, $n .^{o} 1$, cc. 18-34 
I74 Cuadernos de Música Iberoamericana. volumen 3I, 2018
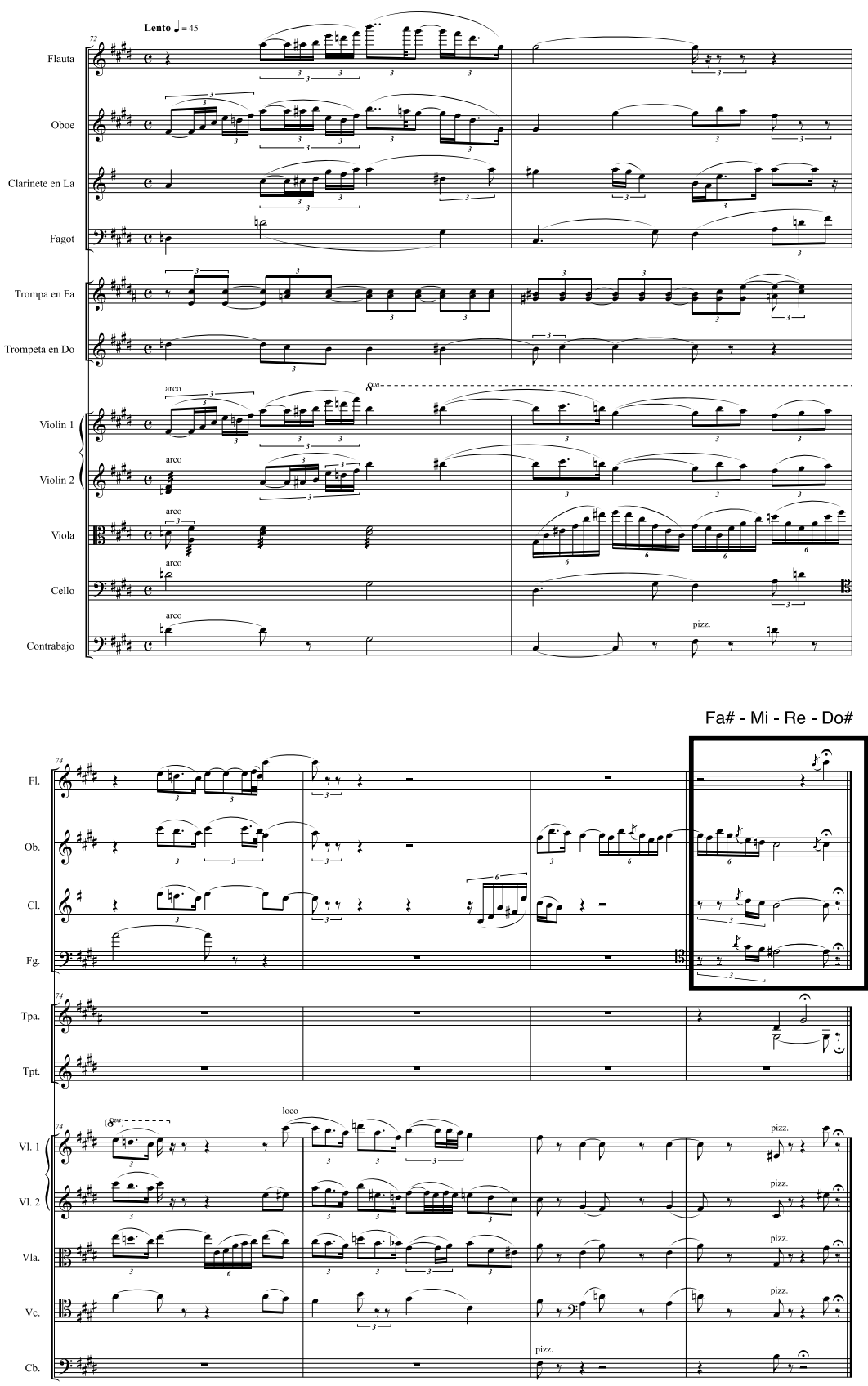

Ejemplo 3. El cielo y Madrid se casan, $n .^{o} 1, c c .72-77$ 
En el mes de mayo de 1928, tal y como se dijo en páginas anteriores, se organizaron en Salamanca una serie de actos conmemorativos para celebrar el centenario del nacimiento de fray Luis de León. Dentro de la serie de eventos que se habían programado se representó, el día 27, el retablo que acabamos de tratar, El cielo y Madrid se casan, con la música de Conrado del Campo. El retablo de fray Luis ${ }^{45}$, del que nos vamos a ocupar ahora, fue escrito y compuesta su música expresamente para esta ocasión, y se estrenó también en el Teatro Bretón de Salamanca el 25 de mayo de 1928. Fue durante lo que se consideró como la "función de gala" del centenario ${ }^{46}$, y contó con la presencia de parte de la familia real española, hecho al que ya hicimos mención en el apartado anterior cuando describimos el ambiente de los teatros en los que se representaban los retablos de Víctor Espinós ${ }^{47}$.

La obra está ambientada en el siglo XVI y en ella se narran diversos momentos de la vida de fray Luis de León: sus enseñanzas como catedrático en la Universidad de Salamanca y la admiración que despierta en sus alumnos; su detención y años de cárcel; y, finalmente, su puesta en libertad y su regreso a las aulas con su inmortal frase "decíamos ayer...". Los personajes siguen la estética de los retablos anteriores y en él podemos encontrar tanto a la clase popular como estamentos más altos del ámbito universitario. En este caso el tono religioso no es aquí tan evidente -aunque está siempre presente como una suerte de telón de fondo de la acción- ya que se hace ahora un mayor hincapié en el mundo universitario y en sus jerarquías históricas.

Desde el punto de vista estructural, es una de las obras más extensas de Víctor Espinós. Comienza con una loa y le siguen tres jornadas divididas en nueve, tres y cinco escenas respectivamente, para las que Conrado del Campo compuso siete números musicales que se conservan íntegramente en el archivo de la SGAE. El primer ejemplo de cadencia andaluza lo encontramos en el segundo número, en un momento en el que en la escena se está brindando por la victoria española en la batalla de Lepanto, por lo tanto, en medio de un tono patriótico muy evidente. Se trata de una cadencia que se repite dos veces sobre el centro tonal de La (tetracordo ReDo-Sib-La) -quinto grado de la tonalidad principal de Re-, que se inserta después de una melodía acompañada de carácter popular que evoca una típica danza española de división ternaria.

${ }^{45}$ V. Espinós: El retablo de fray Luis, Madrid, Editora Nacional, 1947.

${ }^{46}$ Libro del tercer centenario de la canonización de San Isidro (1622-1922), Madrid, Imprenta del Asilo de Huérfanos del Sagrado Corazón de Jesús, 1922.

47 "La función de gala en el Bretón", El Adelanto, Salamanca, 13-5-1928, p. 5. 

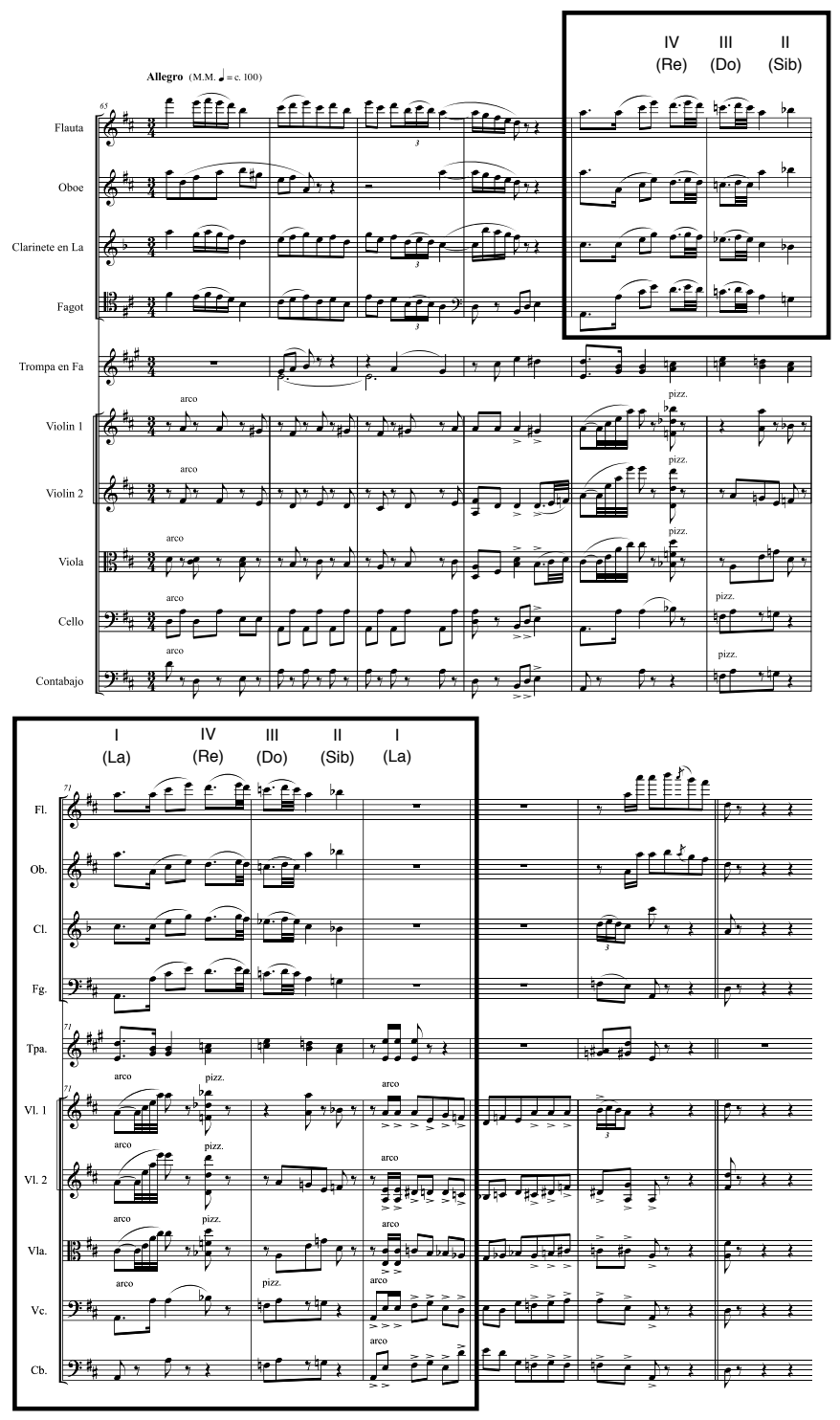

Ejemplo 4. El retablo de fray Luis, $n .^{\circ} 2, c c .65-76$

El siguiente y último ejemplo de cadencia andaluza se encuentra en el número cuatro de este mismo retablo, el cual actúa como preludio de la segunda jornada, en la que se narran los años de presidio a los que estuvo sometido el protagonista, fray Luis de León. La parte central de la pieza está plagada de giros sonoros procedentes del modo frigio, hecho que no hace 
otra cosa más que preparar el terreno para la cadencia andaluza final sobre la nota $\mathrm{Mi}$ (tetracordo La-Sol-Fa-Mi), tal y como se puede observar en la imagen que ofrecemos a continuación. Se trata de un pasaje que presenta una textura contrapuntística e imitativa muy marcada, con desarrollos melódicos y armónicos de carácter cromático que finalmente resuelven en la cadencia mencionada.

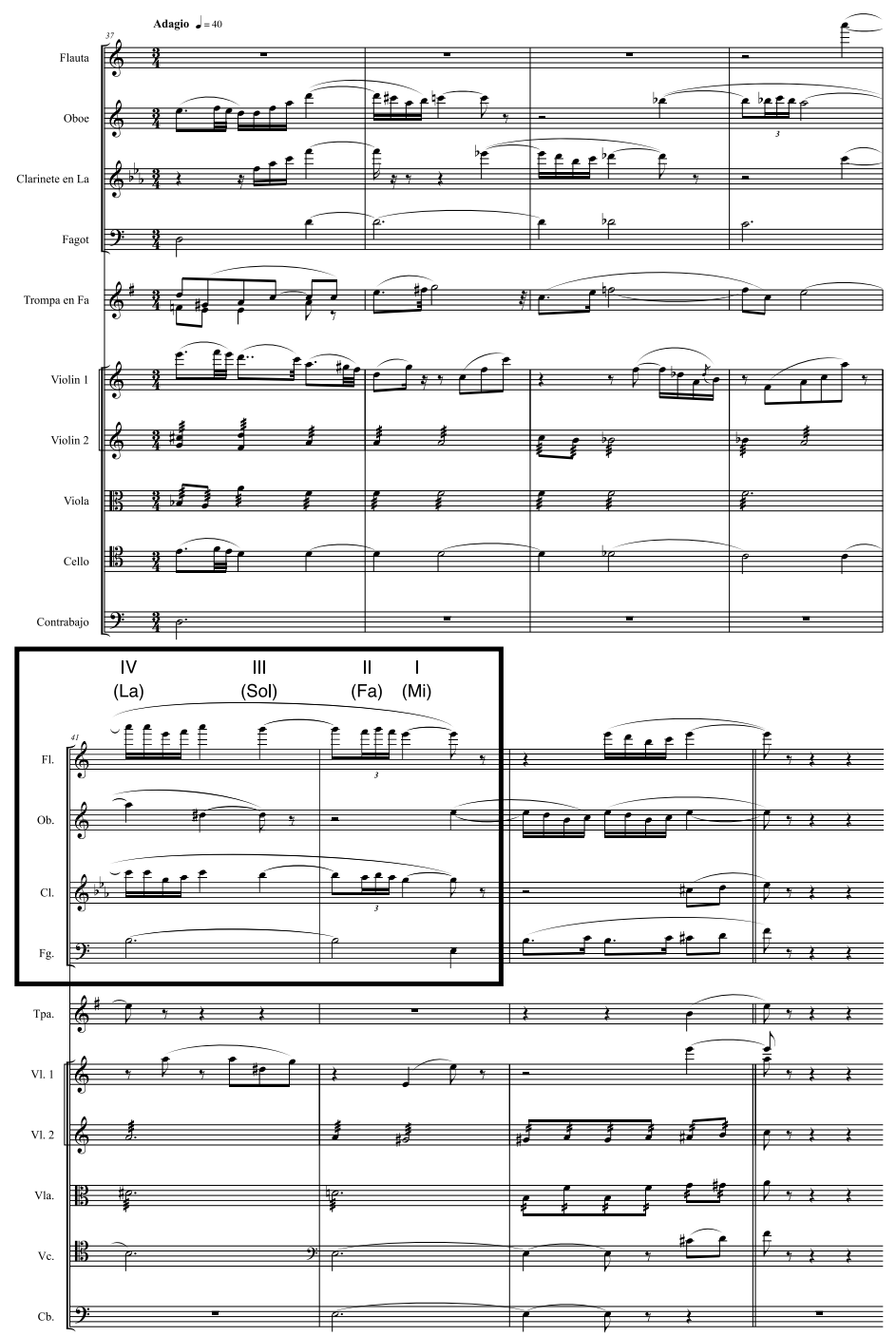

Ejemplo 5. El retablo de fray Luis, $n .^{\circ} 4, c c .37-44$ 
Por último, y antes de las conclusiones de todo lo que acabamos de tratar, ya solo queda comentar qué ocurre con la cuarta pieza, El retablo de los remedios ${ }^{48}$. Se trata de una obra que Víctor Espinós y Conrado del Campo hicieron para conmemorar el primer centenario de la Facultad de Farmacia en el año 1930 y que fue estrenada en el Teatro de la Zarzuela de Madrid el 29 de noviembre de ese mismo año ${ }^{49}$. Comienza con un vejamen en recuerdo a la ciencia farmacéutica y continúa con dos jornadas. La primera de ellas se sitúa en una plaza de Salamanca del siglo XVI y narra una escena de contraste entre la brujería y la ciencia seria que se le presupone a la farmacia. La segunda es una fantasía en la que desfilan todos los fundadores de las universidades españolas ante la ciencia, un personaje que, a tenor de su descripción, posee una fuerte carga patriótica: "personificada en una señorita de soberana hermosura, vestida de un manto de tisú de oro, en el que campea el águila bicéfala en negro y orlan los escudos de las provincias" ${ }^{50}$. Se combinan, por lo tanto, personajes populares (en la primera jornada) con otros más nobles e históricos, siempre en medio de un tono de exaltación de la patria española.

Desde el punto de vista musical la obra presenta un interés menor que las anteriores ya que Conrado del Campo reutiliza los números uno, dos y siete de El retablo de fray Luis. En todos ellos realiza algunas modificaciones que no pretenden otra cosa que adaptarse musicalmente a la nueva escena planteada por Espinós: el primer y segundo números se acortan y el quinto es ampliado considerablemente, tanto al principio como al final, para poder abarcar el desfile de todos los personajes que aparecen en la segunda jornada. En cuanto al empleo de la cadencia andaluza, la modificación realizada en el segundo número prescinde del ejemplo que pusimos antes en El retablo de fray Luis. Sin embargo, el examen de los manuscritos -que son los mismos que los de El retablo de fray Luis- nos lleva a pensar que posiblemente sea esta una obra creada con prisa y sin una reflexión estética profunda, seguramente motivada por la carga de trabajo que el compositor tenía en aquellos años. Por lo tanto, el análisis musical debe remitirnos en este caso a los correspondientes números de El retablo de fray Luis, pieza para la que esta música fue expresamente creada.

\footnotetext{
${ }^{48}$ V. Espinós: "El retablo de los remedios", Libro de oro de la Academia Nacional de Farmacia. Primer centenario de la facultad, Madrid, 1930, pp. 205-225.

${ }^{49}$ Ibid.

${ }^{50}$ Ibid., p. 207.
} 


\section{Conclusiones}

El análisis de la música que Conrado del Campo compuso para los retablos deVíctor Espinós nos ha permitido observar que la presencia del tópico "cadencia andaluza" en este conjunto de obras no es muy abundante. Sin embargo, es precisamente el carácter puntual de este recurso la razón que nos lleva a pensar que se trata de un rasgo estilístico muy meditado por parte del compositor pues, además, el uso que hace de ella es similar en todos los ejemplos tratados: se inserta dentro de un lenguaje compositivo tardo-romántico y dentro de un ambiente claramente españolista y muy patriótico que entronca a la perfección con el contexto literario en el que se ubica la obra deVíctor Espinós. Unas veces aparece en un contexto más popular, acompañando a melodías que nos recuerdan o proceden del folclore castellano; y otras en un estilo más próximo a la música germana de la segunda mitad del siglo XIX marcada por el cromatismo, el desarrollo contrapuntístico y melódico y, en ocasiones, el lenguaje wagneriano.

A lo largo de las páginas anteriores hemos empleado de forma recurrente la etiqueta "tardo-romanticismo" en relación al estilo compositivo de Conrado del Campo. Somos conscientes de lo problemático que puede resultar esta denominación, y en este sentido es necesario aclarar que su uso responde a la propia funcionalidad que posee el término para hacer referencia a un lenguaje musical que combina y evoluciona prácticas heredadas de los años finales del siglo XIX con otros gestos, texturas y procedimientos que formaban parte de una realidad compositiva contemporánea. Por lo tanto, el término no pretende sugerir una completa desconexión entre el caso de estudio y las nuevas propuestas musicales de aquellos años, más bien todo lo contrario, tal y como ha quedado patente a través de los ejemplos musicales analizados y con la vinculación del propio Conrado del Campo a otros ejercicios de renovación teatral, como El teatro del arte de los Martínez Sierra ${ }^{51}$, o el fallido Teatro del peón de música de Manuel Abril, para el que compuso la acción dramática titulada El cuento del pío pío $(1928)^{52}$.

Por otro lado, las conclusiones obtenidas a lo largo de estas páginas revelan un uso constante del tópico "cadencia andaluza" a lo largo de la carrera del compositor. En este sentido, al principio de este trabajo hicimos mención a un estudio mayor centrado en la producción lírica de Conrado del Campo entre 1910 y 1920, en el que se analizan sus tres primeras óperas en aras de alcanzar un objetivo similar al que se ha planteado para el

\footnotetext{
${ }^{51}$ Véanse las siguientes obras de referencia, Carlos Reyero Hermosilla: Gregorio Martínez Sierra y su Teatro de Arte, Madrid, Fundación Juan March, 1980; M. ${ }^{a}$ Luz González Peña: Música y músicos en la vida de María Lejárraga, Logroño, Instituto de Estudios Riojanos, 2009.

52 M. Alonso: Catálogo de obras de Conrado del Campo..., p. 87.
} 
presente artículo: determinar los rasgos identitarios de su producción lírica y ponerlos en relación con el contexto de su época. Así, se ha analizado ya su primera ópera, El final de don Álvaro, compuesta en 1910 a partir de un libreto de Carlos Fernández Shaw, y estrenada en 1911 en el Teatro Real. En ella hemos observado un uso similar de la cadencia andaluza: el compositor la inserta dentro de un canto de trilla puramente castellano -con una sonoridad próxima al modo mixolidio debido a que a veces suprime la sensible- cuya base armónica se corresponde con ese estilo tardo-romántico que hemos comentado y matizado. El hecho de emplear de igual forma un mismo tópico en años tan alejados desde el punto de vista estético como 1910 y 1927 (incluso con un planteamiento técnico similar) nos permite pensar que puede tratarse de un uso constante dentro de su estilo compositivo y, por lo tanto, de un rasgo identitario propio de su producción lírica.

Sin embargo, lo más relevante de todo esto es que este uso de la cadencia andaluza contrasta fuertemente con el que practicaron otros autores del momento, como Isaac Albéniz, Manuel de Falla o Joaquín Turina -pioneros entre muchos otros de estética similar- quienes insertaron el tópico "cadencia andaluza" dentro de un contexto armónico mucho más modal derivado del estilo simbolista de Debussy para crear una visión de la identidad nacional que ha perdurado hasta hoy. Es importante insistir, para no pecar de reduccionistas, que nos estamos refiriendo a un perfil de compositores que usaron el tópico dentro de esa órbita simbolista que asimilaron en su etapa vital de París, y que somos totalmente conscientes así lo dejamos patente en la descripción técnica del tópico elegido- que estamos ante un gesto musical muy recurrente en el folclore castellano y en la tradición lírica española del siglo XIX.

Conrado del Campo, como hemos visto, se valió del mismo tópico en un contexto armónico bien diferente para, a la postre, obtener unos resultados similares: expresar su propia concepción de la identidad musical española. Aunque es evidente que aquellas primeras propuestas de Albéniz, Falla y Turina son las que tendemos a identificar como netamente españolas (o, por qué no decirlo, relacionamos directamente con Andalucía), cabría preguntarse si en las primeras décadas del siglo XX el público se sintió más representado por otras líneas estéticas, como la de Conrado del Campo, ya que, como hemos podido comprobar a lo largo de este estudio, es un modelo de identidad musical que posiblemente sería más acorde y entendible para una audiencia mayoritaria procedente de las clases populares y de una gran de parte la alta sociedad.

Recibido: 9-5-2018

Aceptado: 11-6-2018 